\title{
“Temos que nos reinventar": os professores e o ensino da educação física durante a pandemia de COVID-19 ${ }^{1}$
}

\author{
"We have to reinvent us": teachers and physical education teaching during \\ the COVID-19 pandemic
}

\author{
(iD) Marcos Godoi \\ Doutor em Ciências da Educação \\ Instituto Federal de Educação, Ciência e Tecnologia de Mato Grosso - IFMT. \\ Cuiabá, MT - Brasil. \\ marcos.godoi@cba.ifmt.edu.br \\ Larissa Beraldo Kawashima \\ Doutora em Educação \\ Instituto Federal de Educação, Ciência e Tecnologia de Mato Grosso - IFMT. \\ Cuiabá, MT - Brasil. \\ larissa.kawashima@cba.ifmt.edu.br \\ Luciane de Almeida Gomes \\ Doutora em Educação \\ Universidade Federal de Mato Grosso - UFMT. \\ Cuiabá, Mato Grosso - Brasil. \\ lualgomes@hotmail.com
}

\begin{abstract}
Resumo: No cenário de rápida transformação e de alta incerteza provocado pela pandemia de Covid-19, esta pesquisa identificou os desafios e as aprendizagens dos professores de Educação Física relacionadas ao ensino remoto. Para isso, foi realizado um grupo focal com cinco professores de escolas particulares. Os desafios enfrentados pelos docentes foram: sentimentos de medo e ansiedade; a adaptação para as aulas online e o uso das tecnologias no ensino; a inibição dos alunos para abrir as câmeras; encontrar atividades adequadas para o ensino remoto; a dificuldade em avaliar os alunos; a falta de apoio de algumas famílias. Em relação as aprendizagens, eles indicaram: o aprendizado do uso das TDICs; a intensificação da colaboração com colegas; a adaptação das estratégias metodológicas e o uso da criatividade. O ensino remoto emergencial gerou novos desafios para os professores de Educação Física, mas também oportunizou aprendizagens, incluindo o uso das TDICs no ensino.
\end{abstract}

Palavras-chave: Ensino. Educação física. TDIC. Pandemia. COVID-19.

Abstract: In the scenario of rapid transformation and high uncertainty caused by the Covid-19 pandemic, this research identified the challenges and learning of Physical Education teachers related to remote education. For this, a focus group was held with five teachers from private schools. The challenges faced by teachers were: feelings of fear and anxiety; adaptation to online classes and the use of technologies in teaching; inhibiting students to open the cameras; find suitable activities for remote education; the difficulty in evaluating students; the lack of support from some families. Regarding learning, they indicated: learning how to use TDICs; intensifying collaboration with colleagues; the adaptation of methodological strategies and the use of creativity. Emergency remote teaching created new challenges for Physical Education teachers, but it also provided learning opportunities, including the use of TDICs in teaching.

Keywords: Teaching. Physical education. DICT. Pandemic. COVID-19. 


\section{Introdução}

A pandemia de Covid-19 e a crise sanitária decorrente ocasionou o fechamento de escolas em todo o mundo, impactando mais de 44 milhões de estudantes da Educação Básica no Brasil (UNESCO, 2020). Deste modo, administradores educacionais, diretores de escola e professores começaram a criar estratégias para minimizar as consequências da suspensão de aulas presenciais e promover a continuidade do ensino de forma remota, mediado pelas tecnologias digitais de comunicação e informação (TDICs).

Neste sentido, é importante notar a diferença entre a educação à distância $(\mathrm{EaD})$ e o ensino remoto emergencial (ERE). No caso da primeira, existem concepções teóricas, metodológicas e especificidades desta modalidade de ensino que dão sustentação para a EaD (RODRIGUES, 2020). Por sua vez, no ERE há uma adaptação curricular temporária para dar continuidade as atividades de ensino durante o distanciamento social, envolve o ensino remoto ou o ensino híbrido, este último que alterna atividades à distância e presenciais quando isso for possível (HODGES et al., 2020).

Neste trabalho nos interessamos especificamente pelo trabalho dos professores de Educação Física que atuam na Educação Básica, em escolas privadas. Mesmo que de uma maneira geral essas escolas tenham boa infraestrutura, equipamentos e materiais pedagógicos, a transição do ensino presencial para o ensino remoto não é uma situação simples e requer novas aprendizagens por parte dos professores.

Por exemplo, as aulas de educação física que ocorriam predominantemente nas instalações esportivas, com intensa movimentação e contato corporal entre os alunos, foram suspensas. Vale notar que este é um componente curricular marcadamente identificado pelo saber fazer, pelas vivências e experimentações corporais (ANVERSA et al., 2017; LAZZAROTTI FILHO et al., 2015). Deste modo, os professores desta disciplina se viram diante de um novo desafio, ensinar a cultura corporal de movimento para crianças e adolescentes mediada pelas tecnologias.

Com base nestas considerações iniciais, o objetivo deste estudo foi identificar os desafios e as aprendizagens vivenciadas pelos professores de Educação Física da Educação Básica da rede privada, no período do ensino remoto. A relevância desta pesquisa encontra-se no fato de documentar e divulgar o processo de transição do ensino presencial para o ensino remoto emergencial durante o período de distanciamento social provocado pela pandemia de 
Covid-19. Espera-se que os achados desta pesquisa contribuam para a compreensão do fenômeno em tela. Porém, sem esgotar as possibilidades e ângulos de análise.

\section{Metodologia}

Esta pesquisa de natureza qualitativa, utilizou como dispositivo mediador o grupo focal, técnica de investigação utilizada para coletar dados com ênfase no indivíduo enquanto componente de um grupo (GUIMARÃES, 2006). O grupo focal é constituído e desenvolvido em função do problema de pesquisa, o pesquisador levanta questões relevantes e contextualizadas e constrói um roteiro de trabalho preliminar e flexível (GATTI, 2012).

Para a composição do grupo, o convite para a participação juntamente com o termo de consentimento foi enviado para grupos de WhatsApp de professores. Sete professores responderam positivamente, mas dois professores não puderam participar no dia agendado. $\mathrm{O}$ quadro a seguir mostra o perfil dos cinco colaboradores da pesquisa, sendo que seus nomes foram substituídos por nomes fictícios.

Quadro 1 - Colaboradores da pesquisa

\begin{tabular}{|c|c|c|c|c|c|}
\hline & Escola 1 & \multicolumn{2}{|c|}{ Escola 2} & Escola 3 & Escola 4 \\
\hline Professores & Giovana & Diego & Melissa & Tânia & Tulio \\
\hline Formação & $\begin{array}{c}\text { Universidade } \\
\text { particular }\end{array}$ & $\begin{array}{l}\text { Universidade } \\
\text { pública }\end{array}$ & $\begin{array}{c}\text { Universidade } \\
\text { pública }\end{array}$ & $\begin{array}{c}\text { Universidade } \\
\text { particular }\end{array}$ & $\begin{array}{c}\text { Universidade } \\
\text { particular }\end{array}$ \\
\hline $\begin{array}{l}\text { Tempo no } \\
\text { magistério }\end{array}$ & 11 anos & 20 anos & 18 anos & 13 anos & 9 anos \\
\hline $\begin{array}{l}\text { Turmas que } \\
\text { ensinam }\end{array}$ & $\begin{array}{l}\text { Educ. Inf. e } \\
\text { Ens. Fund. } 1\end{array}$ & $\begin{array}{l}\text { Educ. Inf. e } \\
\text { Ens. Fund. }\end{array}$ & $\begin{array}{l}\text { Educ. Inf. e } \\
\text { Ens. Fund. }\end{array}$ & $\begin{array}{c}9^{\circ} \text { ano e } \\
\text { Ensino Médio }\end{array}$ & $\begin{array}{l}\text { Ens. Fund. } 2 \\
\text { ao } 2^{\circ} \text { ano Ens. } \\
\text { Médio }\end{array}$ \\
\hline $\begin{array}{l}\text { Outros } \\
\text { trabalhos }\end{array}$ & $\begin{array}{c}\text { Animadora de } \\
\text { festa }\end{array}$ & $\begin{array}{l}\text { Em outras } 2 \\
\text { escolas } \\
\text { particulares }\end{array}$ & $\begin{array}{l}\text { Escolinha de } \\
\text { natação }\end{array}$ & $\begin{array}{c}\text { Em escola } \\
\text { pública }\end{array}$ & $\begin{array}{l}\text { Escolinha de } \\
\text { futsal }\end{array}$ \\
\hline
\end{tabular}

Fonte: Elaboração própria.

O grupo focal foi realizado com cinco professores que trabalham em escolas particulares de Cuiabá e um deles trabalha numa escola particular de Campo Verde, estado de Mato Grosso, Brasil. Todos os professores colaboradores são licenciados em Educação Física, três estudaram em instituições particulares e dois em instituições públicas. Além de trabalharem com a Educação Física escolar, eles têm outros trabalhos, tais como: animação de festas, aulas em 
outras escolas privadas ou públicas e o treinamento esportivo. Ademais, os colaboradores têm entre 9 e 20 de experiência profissional no ensino.

A reunião online foi realizada no dia 4 de julho de 2020 por meio do Google Meet e teve a duração de uma hora e quarenta minutos. O vídeo do grupo focal foi transcrito usando o programa Trint e depois revisado por um dos pesquisadores. As falas dos professores e dos pesquisadores foram numeradas, de acordo com seu turno de fala (Tf) no diálogo, por ex.: Tf 1, Tf 2 , Tf 3, etc. Os dados foram analisados por meio de análise temática contínua (PAILLÉ; MUCHIELLI, 2012), sendo que no momento da análise foram identificadas e separadas as unidades de significação, ou seja, uma frase ou conjunto de frases ligadas a um mesmo tema. Os temas e os subtemas derivados dos primeiros, daqui em diante serão apresentados denominados de categorias.

Na próxima parte do artigo serão apresentados os resultados da pesquisa agrupados em duas categorias: a) os desafios relacionados ao ensino remoto e b) as aprendizagens relacionadas ao ensino remoto.

\section{O ensino remoto: desafios e aprendizagens dos professores de educação física}

Segundo os professores colaboradores desta pesquisa, eles ficaram sabendo da mudança do ensino presencial para o ensino remoto no dia 20 de março de 2020. Todos os docentes declararam que as escolas em que atuam ofereceram reuniões e treinamento para utilizar as ferramentas tecnológicas no ensino remoto.

Apesar disso, fica a dúvida se essa formação ou treinamento foi suficiente para atuar no ERE ou não. Porém, nenhum dos colaboradores aprofundou neste aspecto, sendo um não dito em suas falas. Vale notar que a pesquisa do Instituto Península (2020) revelou que somente 49,2\% dos professores das escolas particulares declararam ter recebido suporte ou treinamento para o ensino remoto. No caso da nossa pesquisa, os colaboradores da pesquisa relataram uma série de desafios ocasionados pela nova forma de ensino.

\section{a) Desafios enfrentados pelos professores relacionados ao ensino remoto}

Primeiramente, vale destacar que a transição do ensino presencial para o ensino remoto desencadeou sentimentos de medo, angústia, ansiedade e a necessidade de se superar que constituíram-se como um desafio para os docentes. 
Tf 1: [...]. Foi impactante no primeiro momento. Todo mundo estava assustado porque ia ter que gravar a aula, mostrar seu rosto e quando você grava a aula fica tudo registrado. Então o cuidado com as palavras teria que ser redobrado. [...]. (TÂANIA, 2020).

Tf 3: O primeiro impacto foi "Eu vou ficar desempregada". Mas os diretores falaram: "Jamais nós iremos tirar a Educação Física. Nessa hora é essencial as crianças fiquem ativas!” [...]. (GIOVANA, 2020).

Tf 9: [...]. Quando falaram que ia começar as aulas online eu fiquei dois dias sem dormir! Planejava e ficava com medo de não dar certo. Tive alguns encontros com a Melissa antes, fizemos algumas vídeo-aulas e vamos lá ver como funciona (DIEGO, 2020).

Tf 19: O meu maior desafio é a cada aula superar, se uma foi melhor, a outra tem que ser melhor ainda. Então eu me cobro muito. Se eu faço uma aula gostosa e todo mundo participou, então eu quero fazer cada vez melhor. [...]. (GIOVANA, 2020).

A transição do ensino presencial para o ensino remoto aconteceu de forma muito rápida, exigindo uma resposta de adequação quase que imediata, o que justifica os sentimentos compartilhados pelos professores de insegurança, ansiedade etc. Corroborando estes resultados, na segunda fase de uma pesquisa do Instituto Península (2020a) ${ }^{2}$ realizada no mês de maio, mostrou que $67 \%$ dos professores estavam ansiosos, 38\% cansados, 36\% entediados, 35\% sobrecarregados e $34 \%$ estressados com a nova rotina do ensino remoto.

Já na terceira fase desta mesma pesquisa, realizada no mês de agosto ${ }^{3}, 64 \%$ dos professores estavam ansiosos, 53\% sobrecarregados, $46 \%$ cansados e $42 \%$ estressados (INSTITUTO PENÍNSULA, 2020b). Nota-se que houve um aumento de $18 \%$ no percentual de professores que se sentiam sobrecarregados e de $8 \%$ no percentual de professores que se sentiam cansados e estressados.

Além disso, no novo contexto de ensino modificado pela pandemia, um dos desafios apontados pelos professores foi a adaptação para as aulas online e dominar as ferramentas tecnológicas.

Tf 7: [...]. É aí que vem o desafio, porque a prática nossa tinha que ser ao vivo, não é você mandar o vídeo e o aluno faz. Eu até prefiro ao vivo porque aí você vê o aluno fazendo. [...]. (TULIO, 2020).

Tf 16: [...] eu acho que primeiramente foi o domínio da ferramenta. Aquele medo de você não conseguir dominar a ferramenta, foi um dos desafios pra mim. [...]. (DIEGO, 2020).

Tf 17: Eu acho que meu maior desafio foi no início mesmo, essa adaptação para as relação as aulas online. [...] quando a gente está em aula online alguém pode passar atrás da gente, o barulho na nossa casa, porque meus sobrinhos moram comigo. Por isso que eu prefiro estar dentro da escola para não acontecer alguma situação como essa. [...]. Então todo esse cuidado é gigantesco [...]. (TÂNIA, 2020). 
Ainda em relação aos desafios, os professores destacaram a inibição ou resistência dos alunos em ligar a câmera durante as aulas online. Na opinião dos professores, isso dificulta a avaliação dos alunos e gera dúvidas se os alunos estão acompanhando ou não a aula.

Tf 1: [...]. Muitos alunos também não queriam aparecer na tela. A gente [escola] tornou obrigatório o aluno abrir a tela do computador ou do celular. Ele estar uniformizado, porque a gente está fazendo uma aula. Como o professor tem que ir uniformizado, o aluno tem que estar uniformizado (TÂNIA, 2020).

Tf 9: [...]. Tem aluno que liga a câmera, o outro não liga, o outro liga deixa e sai. Então, como que eu vou fazer? Para você avaliar nas aulas presenciais já é complicado. [...] e como você vai fazer essa avaliação à distância? [...]. Mas nós não podemos obrigá-los, tem a questão familiar também (DIEGO, 2020).

Tf 5: Eu fico chateada com as aulas do Ensino Fundamental 2, porque eles não ligam a câmera. Me dá uma desmotivada, porque eu fico falando e mostrando algumas coisas pra fazer e pergunto: "E aí Fulano, você está participando?" Alguns têm vergonha de falar, eu acho que é por causa da idade, na adolescência eles ficam meio retraídos, mas eles respondem no chat. [...]. (MELISSA, 2020).

Tf 26: [...] Só que aí eu chego e digo: "Eu quero câmera ligada. Só que a outra professora que entra não está nem aí para isso. [...]. Então eu fiz um acordo com eles de sinceridade, quem quer ligar a câmera liga, quem não quer tranquilo. (DIEGO, 2020).

A não presença física na interação no ambiente virtual também foi apontado como uma dificuldade na educação à distância (CRUVINEL et al., 2017; LAZZAROTTI FILHO et al., 2015) e no ensino remoto durante a pandemia na formação profissional em educação física (VAREA; GONZÁLEZ-CALVO, 2020; GODOI et al., 2020). No período do ensino remoto, a ausência corporal nas aulas tem provocado um misto de emoções, pois os professores em formação sentem falta do contato físico com os alunos e acreditam que a educação física está perdendo sua identidade (VAREA; GONZÁLEZ-CALVO, 2020). Identidade esta, caracterizada nas aulas presenciais pelo movimento corporal e interações proporcionadas pelos jogos, esportes, dança, ginástica e lutas nas aulas de educação física.

Os professores também apontaram a diminuição da participação dos alunos nas práticas por meio do ensino remoto ao longo dos anos escolares.

Tf 7: A dificuldade é que conforme as turmas vão ficando mais velhas, o interesse vai diminuindo. [...]. Teoria se eu mandar eles fazem, prática eles não querem. Eu acho que principalmente por esse fator vergonha, eles estão numa outra fase (TULIO, 2020).

Tf 36: [...]. Ele [um aluno com sobrepeso] teve vergonha de fazer ali na frente da câmera com todo mundo, mas o importante é que ele fez e me mandou o vídeo depois (TÂNIA, 2020). 
Como os professores colaboradores de nossa pesquisa apontaram, a vergonha e a inibição dos alunos, seja devido a seu corpo ou a sua performance corporal pode dificultar para que eles liguem suas câmeras durante as aulas online. Além disso, pode ocorrer que o ambiente em que vivem não seja adequado para estudo, com interferência de ruídos e de pessoas.

Outro desafio relacionado ao ERE apontado pelos professores é encontrar atividades adequadas para a nova forma de ensino.

Tf 9: [...] a grande dificuldade é de você conseguir encontrar atividades individuais. Quando você vai procurar em qualquer material didático, toda atividade é em dupla ou em pequenos ou grandes grupos. Como você vai trazer isso para a realidade individual? [...]. (DIEGO, 2020).

Tf 11: [...], porque não é fácil você adaptar uma atividade, justamente como o professor Diego falou, que não se acha atividade para o aluno fazer individual e no caso online ainda é mais difícil, [...]. (TIAGO, 2020).

Tf 15: [...] Porque a questão da atividade individual também é um desafio. Tem que "suar a camisa" para a gente adaptar as atividades para fazer individual. [...] (MELISSA, 2020).

De fato, a natureza das aulas presenciais de educação física é por essência coletiva, um grupo de alunos se reúne com o professor para aprender sobre as práticas corporais que em sua maioria são atividades coletivas: os esportes, as danças, as lutas, as brincadeiras e jogos, etc. No ensino remoto os alunos e o professor se reúnem no ambiente virtual, mas este não permite uma interação corporal tal qual nas aulas presenciais. Deste modo, os professores precisam encontrar atividades de ensino que os alunos possam realizar individualmente ou quando muito, interagindo com algum membro da família.

Outro desafio apontado pelos professores foi a questão da dificuldade de avaliar e de dar feedback para os alunos no ensino remoto.

TF 9: [...] para você avaliar dentro das aulas presenciais já é complicado, para mim a pior parte. Não é fácil avaliar por uma série de fatores e como você vai fazer essa avaliação à distância? Será que esse aluno estava lá mesmo? Por quê ele não estava? Por quê ele não participou? Eu acho que a questão avaliativa também está pesando muito. Será que eu vou ser injusto? Será que ele está me fazendo de otário? [...]. (DIEGO, 2020).

Tf 11: [...]. A questão da avaliação, tem aluno que nunca assistiu uma aula e tem aluno que participa todo o dia. Aí aquele aluno que não participa, ele volta e ainda vai ficar tirando sarro! É uma situação que a gente tem que pensar bem [...]. (TULIO, 2020).

Tf 26: [...]. Agora a partir do momento que você está à distância, o feedback fica mais complicado. [...]. O método de avaliação por participação é fácil de fazer. Agora, espera aí, além de estar a distância você vai ter que pensar como que está o desempenho dessa criança, aí fica mais difícil. [...]. (DIEGO, 2020). 
O desafio de como avaliar e a dificuldade de dar feedback para os alunos no ERE foram verbalizados especialmente pelos professores Diego e Tulio. De fato, alguns autores consideram a avaliação uma das tarefas mais difíceis que os professores de educação física têm que lidar em seu trabalho pedagógico (LÓPEZ-PASTOR et al., 2013).

$\mathrm{Na}$ educação física, os professores tendem a classificar os alunos em fatores supérfluos como as atitudes, o esforço, a participação e a frequência nas aulas (PENNEY et al., 2009). Por sua vez, Hay (2006), defende que a avaliação autêntica na educação física deveria ser baseada no movimento e captar os processos cognitivos, psicomotores e do domínio afetivo implicados nas atividades corporais. No caso do ensino remoto, este tipo de avaliação se torna ainda mais complicado de ser realizado.

Os professores também apontaram como desafio saber lidar com as reclamações ou com a falta de apoio das famílias na realização das tarefas dos filhos.

Tf 1: [...]. Apesar que os pais não querem ter dificuldade, só facilidade. Alguns falam que o papel de ensinar é somente do professor. Isso é inadmissível! Se a tarefa está em casa, é para fazer em casa. Às vezes tinha reclamação que não era pra ficar mandando tarefa, excesso de atividade, mas o aluno tem que se reinventar e querer fazer. Já tem aquele aluno que não fazia mesmo no ensino presencial, imagina com o online? (TÂNIA, 2020).

Tf 9: [...]. Evitar ao máximo constrangimento da família, eu sempre aviso com uma semana de antecedência o que eu vou precisar. Chega na outra semana o aluno fala: "O meu pai não teve tempo de sair para comprar, estava tudo fechado." [...]. (DIEGO, 2020).

Tf 11: [...]. Na ginástica tinha um exercício lá de elevação pélvica, fizeram. Depois a coordenadora veio falar comigo que a mãe de uma aluna não gostou porque a filha dela estava com um short e se sentiu incomodada. Eu fico chateado, porque se ela sabe que nossas aulas são práticas e sabe a roupa que tem que usar [...], ela tinha opção de não fazer, eu não obriguei ninguém. (TULIO, 2020).

Por outro lado, a professora Melissa disse que as críticas das famílias são frequentes no contexto da escola particular, mas que ela não leva muito em consideração, alguns pais não gostam, mas outros elogiam o trabalho.

Tf 15: Lá na escola onde eu trabalho, os pais reclamam até nas aulas presenciais. [...], a coordenação falou que todos os dias reclamam de alguma coisa, não é só das aulas de educação física, de outras aulas também. Isso é chato, mas não me incomoda. Eu não dou moral. Eu fiz um jogo, aí uma mãe mandou mensagem pra mim falando que eu estava caçando treta com essa brincadeira, aí outros dois pais ligaram na escola elogiando (MELISSA, 2020).

A esse respeito, a pesquisa de Fevorini e Lomônaco (2009) com famílias de classe média, mostrou que a expectativa de ascensão social por meio da escola torna esses pais e mães 
verdadeiros "profissionais" em acompanhamento escolar, razão pela qual são bastante exigentes e atentos em relação ao trabalho da escola. Ademais, não há uma convergência muito grande nas críticas, um aspecto que era elogiado por uma das famílias era criticado por outra família na mesma escola.

Em síntese, os desafios enfrentados pelos professores relacionado ao ERE apontados no grupo focal foram: lidar com sentimentos de medo, angústia, ansiedade e de se superar em relação a nova forma de ensino; a adaptação para as aulas online e o domínio das ferramentas tecnológicas para o ensino; a inibição dos alunos para abrir as câmeras; encontrar atividades adequadas para o ensino remoto; a dificuldade de avaliar e de dar feedback para os alunos; saber lidar com as reclamações e falta de apoio das famílias.

Esses achados são corroborados parcialmente com os resultados da terceira fase da pesquisa do Instituto Península (2020b), que revelou que os desafios para os professores no ensino remoto são: manter o engajamento dos alunos (64\%), o distanciamento e perca de vínculo com os alunos (54\%), a falta de formação para lidar com o ERE (49\%), a falta de conhecimento das TDICs (46\%), a falta de um ambiente adequado para trabalhar em casa (45\%), lidar com os pais ou responsáveis (38\%), o lado emocional do trabalho (34\%). Vale notar que esta pesquisa foi realizada com professores de diferentes disciplinas e de escolas públicas e privadas. O principal desafio apontado nesta pesquisa foi a falta de equipamentos e conectividade dos alunos (79\%). No caso da nossa pesquisa, os professores colaboradores das escolas particulares em nenhum momento do grupo focal relataram este tipo de desafio, ou seja, os alunos que eles ensinam têm acesso às tecnologias e não tem problemas de conectividade.

\section{b) Aprendizagens dos professores relacionadas ao ensino remoto}

De um modo geral, os professores disseram que dominavam pouco as TDICs e que com o ensino remoto tiveram que aprender a utilizar tais tecnologias:

Tf 34: Eu acho que o meu maior aprendizado mesmo foi com a tecnologia, eu não gosto muito de fazer nada no computador. [...] foi um grande aprendizado estar aqui manuseando essa ferramenta, aprender a compartilhar uma tela, ligar o microfone, a câmera. Então eu acho que eu estou aprendendo muito! [...]. Até a questão de falar no vídeo é um pouco mais complicado para gente que gosta de estar na relação face a face (MELISSA, 2020).

A esse respeito, pesquisas sobre a integração das TDICs na formação profissional em educação física presencial (BIANCHI; PIRES, 2015) e sobre a formação em educação física à distância (CRUVINEL et al., 2017) também constataram dificuldades relacionadas à 
insegurança e não domínio das TDICs pelos professores do Ensino Superior. Deste modo, podemos dizer que o ERE potencializou o aprendizado do uso das TDICs pelos professores.

Outra aprendizagem destacada por eles é que neste novo contexto cheio de desafios, a colaboração com os colegas se intensificou e proporcionou trocas de experiências, observação, críticas e sugestões dos pares, apoio e ajuda dos colegas.

Tf 19: [...]. Porque no primeiro dia, [...] eu pedi para umas colegas assistirem minha aula [online]. Elas disseram: "Você está muito técnica! Não precisa ser assim, seja você mesma. Igual você dá suas aulas, você brinca!" Na segunda aula elas falaram: "Giovana, $100 \%$ você, seja você nas aulas!" Isso me fortaleceu muito e fez eu melhorar cada vez mais [...]. Nem todos gostam de ouvir críticas. E eu aprendi muito a ouvir e aceitar também, melhorar cada vez mais. [...] (GIOVANA, 2020).

Tf 36: Eu vejo que a gente está aprendendo um com o outro, a partir do momento que a gente aprende um com o outro, nós nos tornamos melhor a cada dia (GIOVANA, 2020).

Tf 38: [...]. Então eu acho que aumentou essa troca de informação e conversa, essa aproximação da gente com os outros professores [de outras áreas] se aproximou muito (DIEGO, 2020).

Deste modo, o novo contexto de ensino remoto mediado pelas tecnologias, estimulou os laços profissionais e a colaboração entre os pares criando, mesmo que espontaneamente, comunidades de aprendizagem que enfatizam a importância de conhecimentos que ocorrem tanto nos contextos de ensino como em contextos profissionais (HARMENNESS et al., 2019). Nessas comunidades professores aprendem juntos e oferecem suporte à aprendizagem e a solução de problemas (DARLING-HAMMOND, 2019).

Ademais, a capacidade de aprender e ter habilidade e vontade de trabalhar com os outros para avaliar o próprio desempenho é uma característica importante da expertise adaptativa. Assim, trabalhar em equipes em que uns aprendem uns com os outros é extremamente importante. Nesses contextos colaborativos, os professores agradecem ao invés de refutar esse feedback (HARMENNESS et al., 2019).

Outro aprendizado que os professores verbalizaram foi a adaptação das estratégias metodológicas para o ensino remoto, seja promovendo apresentações de dança pelos estudantes envolvendo um membro da família (Tânia) ou apresentações de dança usando o tapete "mágico" como palco e como recurso lúdico (Giovana), seja promovendo trabalhos de grupos, sorteios e a criação de desafios para estimular a participação dos alunos (Tulio). 
Tf 1: [...]. Um aluno falou assim: "Professora, mas eu não sei dançar!” Eu falei: "Gente a dança é a expressão do movimento. Então você vai dançar da forma que você conseguir! Aí um colocou Shakira, outro colocou o sertanejo, outro lambadão, outro colocou música de balé. O importante era ter um membro da família do lado apresentando. [...]. (TÂNIA, 2020).

Tf 11: Como o professor Diego falou, não se acha facilmente atividade para o aluno fazer individual e no caso online ainda é muito difícil. Então eu faço trabalhos em grupos aí dá aquela disputa, ou eu faço um sorteio (TULIO, 2020).

Tf 19: [...]. Eu fiz uma festa junina adaptada, [...]. Eu usei o tapete mágico, que foi nosso palco. [...] e falei: "Vocês vão apresentar para o pai de vocês e para os professores que estão aqui." [...] e eles deram um show. Eu levei muita coisa diferente para minha aula online pra ficar mais gostosa, usando os materiais que tem em casa, o balde, o tapete a vassoura. [...] fizemos uma aula fantasiados de super heróis. Então intercalei muita coisa, dança, lutas, jogos (GIOVANA, 2020).

Ainda em relação a adaptação das estratégias metodológicas, houve também uma preocupação em promover atividades práticas nas aulas de educação física para compensar o desgaste ocasionado pelo confinamento e pelas aulas online, bem como motivar os alunos e também desenvolver uma abordagem mais dialógica e empática com os alunos, conversando sobre como eles se sentem no período de distanciamento social.

Tf 1: [...]. Eu trabalho com eles mais prática, porque eles têm a teoria 100\% durante a semana, é muito puxado. Eu vou na teoria também, só que a minha teoria é mais curta. Às vezes eu intercalo. Eles mesmo pedem a teoria para que não precisem abrir as câmeras (TÂNIA, 2020).

Tf 3: A educação física tem que fazer o diferencial. Quando eu inicio a aula eu falo: “Afasta o sofá, a cadeira, levanta o astral, energia positiva, sorriso no rosto!” [...]. Eu fico muito admirada de ver que os pais estão participando, às vezes os avós e até os animais de estimação! [risos] Então eu estou na profissão que eu amo e eu faço com prazer! (GIOVANA, 2020).

Tf 16: [...]. O meu filho faz essas aulas online também [...], quando ele termina a aula, parece que ele fez 20 aulas presenciais! [...] O cansaço, o abatimento, a fisionomia dele está apática. Então, a primeira coisa que eu pensei é que tem que tirar essa gurizada desse marasmo, [...] (DIEGO, 2020).

Tf 34: Está sendo um grande aprendizado também buscar outras maneiras de ensinar, [...]. Eu estou indo assim mais para o diálogo, esse vínculo social com os nossos alunos. No início da minha aula eu faço uma retrospectiva do que a gente fez na aula anterior e depois pergunto: "Como é que foi o seu dia? Como foi essa semana? Como você está lidando com essa quarentena? O que você tem comido para que seu sistema imunológico esteja ok?” [...] (MELISSA, 2020).

Outro aspecto que os professores destacaram referente as aprendizagens deste período foi o uso da criatividade no ensino, seja realizando mais leituras e pesquisas, seja adaptando o planejamento, as atividades e as estratégias metodológicas ou testando o que funciona ou não e a habilidade de improvisar no "calor" da aula. 
Tf 36: Nesse momento de isolamento a gente tem que usar a criatividade, aprender com o outro, temos que nos reinventar. [...]. Nós estamos buscando cada vez mais, voltamos a estudar de novo. [...]. Eu comecei a ler mais, a buscar mais conteúdos, apesar que eu sempre tento inovar os conteúdos da Educação Física, [...] (TÂNIA, 2020).

Tf 5: Igual a Giovana falou, a gente vai usando coisas que tem em casa, copo, fita crepe, barbante, balde, cabo de vassoura é mais ou menos isso, eu acho que a gente está indo no mesmo caminho. Eu gosto de assistir os vídeos da Educação Física da Depressão [no Facebook]. Lá tem várias atividades que dá pra gente usar ou que vai adaptando. Às vezes eu planejo uma tarefa aí o aluno fala que não tem isso em casa. Aí na hora você tem que tirar uma carta da manga, igual quando a gente está na quadra mesmo, [...] (MELISSA, 2020).

Tf 7: [...]. Aí as práticas eu vou criando, eu sigo também a "Educação Física da Depressão", adapto muita coisa e eu vou criando, inventando algumas coisas. [...] (TULIO, 2020).

Tf 9: [...]. Eu estou programando aula de semana a semana, tentando adaptar da melhor forma. E depois que eu percebi que não vai voltar tão cedo, eu adaptei o meu planejamento de acordo com as possibilidades. É aquilo que a vocês já disseram, é vassoura, é bola, é balde, é chinelo, é bolinha de papel, é o que tem (DIEGO, 2020).

Tf 36: [...]. Aí nós vamos buscar os materiais, vamos ver se dá certo. Todas as minhas aulas eu sempre faço um teste antes. [...]. (TÂNIA, 2020).

Todos esses aspectos verbalizados pelos professores: leitura e pesquisa, adaptação, experimentação e capacidade de improvisação nas aulas podem estar presentes tanto no ensino presencial quanto no ensino remoto. Sobre o uso da criatividade no ensino, Woods (1995) destaca que o ensino criativo compreende a imaginação, a capacidade de "ensaiar potenciais interações antes do acontecimento. Este processo é acompanhado por adaptabilidade, flexibilidade e uma prontidão e facilidade para a improvisação e experimentação" (p. 132).

Vale destacar que educar sobre ou por meio dos formatos midiáticos e tecnológicos não é um trabalho fácil, uma vez que nem todos os professores se sentem seguros ou capacitados. Em todo caso, tal como o professor no final de uma aula presencial, é preciso refletir sobre o papel dos dispositivos tecnológicos nas aulas de educação física e registrar os avanços pedagógicos (LEIRO; ARAÚJO; SOUZA, 2019). Isto também vale para o ensino remoto emergencial. Ademais, tais aprendizagens poderão ser incorporadas nas práticas pedagógicas num cenário futuro de ensino presencial ou de ensino híbrido, que alterna atividades presenciais com atividades à distância.

Em síntese, em relação às aprendizagens dos professores no período de ensino remoto, eles destacaram no grupo focal: o aprendizado do uso das TDICs; a intensificação da 
colaboração com colegas; a adaptação das estratégias metodológicas para o ensino remoto e o uso da criatividade no ensino.

\section{Considerações finais}

A pandemia forçou milhões de pessoas em todo mundo a manterem o distanciamento social como forma de prevenção, mudou hábitos de higiene, impactou a economia, agravou a crise e promoveu ainda mais desemprego. Os professores tiveram que se adaptar à necessidade de distanciamento social e o ensino presencial foi substituído pelo ensino remoto emergencial mediado pelas TDICs. Nesse contexto de rápida transformação na educação e de alta incerteza quanto ao futuro, esta pesquisa identificou os desafios e as aprendizagens dos professores de Educação Física relacionadas ao ERE.

No que tange aos desafios enfrentados pelos professores, eles destacaram: lidar com sentimentos de medo, angústia, ansiedade e a necessidade de se superar em relação a nova forma de ensino; a adaptação para as aulas online e o domínio das ferramentas tecnológicas para o ensino; a inibição dos alunos em não abrir as câmeras nas aulas online; a dificuldade em encontrar atividades adequadas para o ensino remoto; a dificuldade de avaliar e de dar feedback para os alunos; saber lidar com as reclamações e falta de apoio de algumas famílias.

Em relação as aprendizagens, os docentes indicaram: o aprendizado do uso das TDICs no ensino; a intensificação da colaboração com colegas; a adaptação das estratégias metodológicas para o ensino remoto e o uso da criatividade no ensino, em especial fazendo mais pesquisas para o planejamento do ensino, bem como experimentando e adaptando atividades para o contexto de ensino remoto.

Entendemos também que a nova forma de ensino ocasionada pela pandemia que requer o uso da tecnologia e conectividade com a Internet pode gerar ainda mais desigualdade em termos de desempenho escolar entre alunos de escolas particulares e de escolas públicas, ou mesmo entre alunos de escolas públicas que têm acesso às TDICs e aqueles que não têm. No entanto, diante da situação inédita as escolas e os professores não tiveram muita escolha, tiveram que se adaptar e se reinventar.

O período da pandemia da Covid-19 impôs às escolas, aos professores, alunos e famílias uma nova forma de ensino. Se os professores não dominavam ou dominavam pouco as ferramentas tecnológicas, a pandemia potencializou sua aprendizagem e seu uso no contexto de ensino. Os professores de educação física tiveram que transferir suas aulas das quadras esportivas, campos e piscinas para a frente das telas do computador ou do celular. Eles 
adaptaram espaços e materiais, pesquisaram conteúdos e atividades pedagógicas, implementaram outras estratégias metodológicas, estabeleceram novas formas de comunicação e interação com seus alunos. Como destaca a fala de uma das colaboradoras dessa pesquisa, os professores tiveram "que se reinventar"!

\footnotetext{
${ }^{1}$ Esta pesquisa não contou com nenhum tipo de financiamento das agências de fomento. Os autores declaram não haver conflito de interesses.

${ }^{2}$ A amostra desta pesquisa foi constituída por 7773 respondentes, sendo $2 \%$ da rede federal, $41 \%$ da rede estadual, $45 \%$ da rede municipal e $15 \%$ da rede privada de ensino.

${ }^{3} \mathrm{Na}$ terceira fase desta pesquisa, a amostra foi composta por 3893 respondentes, sendo $2 \%$ da rede federal, $30 \%$ da rede estadual, $53 \%$ da rede municipal e $15 \%$ da rede privada de ensino.
}

\section{Referências}

ANVERSA, Ana Luiza B. et al. A prática reflexiva na formação de professores de educação física na modalidade EaD. Revista Brasileira de Ciência e Movimento, v. 25, n. 2, p. 122-136, 2017.

BIANCHI, Paula; PIRES, Giovani de Lorenzi. Cultura digital e formação de professores de educação física: estudo de caso na Unipampa. Movimento, Porto Alegre, v. 21, n. 4, p. 10251036, 2015.

CRUVINEL, Fernanda et al. A dinâmica, os principais problemas e as qualidades no desenvolvimento de um curso de licenciatura em Educação Física na modalidade à distância. Pensar a Prática, Goiânia, v. 18, n. 3, p. 1-15, jul./set. 2015.

DARLING-HAMMOND, Linda et al. A elaboração de programas de formação de professores. In: DARLING-HAMMOND, Linda; BRANSFORD, John. (Org.). Preparando os professores para um mundo em transformação. Porto Alegre: Penso, 2019, p. 333-377.

FEVORINI, Luciana Bittencourt; LOMÔNACO, José Fernando Bittencourt. O envolvimento da família na educação escolar dos filhos: um estudo exploratório com pais das camadas médias. Psicologia da Educação, São Paulo, n. 28, p. 73-89, $1^{\circ}$ sem. de 2009.

GATTI, Bernadete Angelina. Grupo focal na pesquisa em ciências sociais e humanas. Brasília, DF: Liber Livro, 2012.

GODOI, Marcos et al. O ensino remoto durante a pandemia de covid-19: desafios, aprendizagens e expectativas dos professores universitários de educação física. Research, Society and Development, v. 9, n. 10, p. 1-19, 2020.

GUIMARÃES, Valter Soares. O grupo focal e o conhecimento sobre identidade profissional dos professores. In: PIMENTA, Selma Garrido; GHEDIN, Evandro; FRANCO, Maria Amélia (org.). Pesquisa em educação: alternativas investigativas com objetos complexos. São Paulo: Loyola, 2006, p. 149-163. 
HAY, Peter J. Assessment for learning in physical education. In: KIRK, David; MACDONALD, Doune; O'SULLIVAN, Mary. (Org.). The handbook of physical education. London: Sage, 2006, p. 312-325.

HAMMERNESS, Karen et al. Como os professores aprendem e se desenvolvem. In: DARLING-HAMMOND, Linda; BRANSFORD, John. (Org.). Preparando os professores para um mundo em transformação. Porto Alegre: Penso, 2019, p. 306-332.

HODGES, Charles; MOORE, Stephanie; LOCKEE, Barb; TRUST, Torrey; BOND, Aaron. The Difference Between Emergency Remote Teaching and Online Learning. March 27, 2020. Recuperado em: https://er.educause.edu/articles/2020/3/the-difference-between-emergencyremote-teaching-and-online-learning Obtido em: 22 de agosto de 2020.

INSTITUTO PENÍNSULA. Relatório de pesquisa: Sentimento e percepção dos professores brasileiros nos diferentes estágios do coronavírus no Brasil. Estágio intermediário, maio de 2020a. Disponível em: https://institutopeninsula.org.br/wp-

content/uploads/2020/05/Covid19_InstitutoPeninsula_Fase2_at\%C3\%A91405-1.pdf Consulta em: 24 de agosto de 2020.

INSTITUTO PENÍNSULA. Relatório de pesquisa: sentimento e percepção dos professores brasileiros nos diferentes estágios do coronavírus no Brasil. Estágio controlado - agosto de 2020. São Paulo: Instituto Península, 2020b. Disponível em:

https://institutopeninsula.org.br/wp-content/uploads/2020/08/Sentimentos_-fase-3.pdf; Acesso em: 5 de outubro de 2020.

LAZZAROTTI FILHO, Ari et al. (2015). A dinâmica, os principais problemas e as qualidades no desenvolvimento de um curso de licenciatura em educação física na modalidade à distância. Pensar a Prática, v. 18, n. 3, p. 636-50, 2015.

LEIRO, Augusto Cesar Rios; ARAÚJO, Allyson Carvalho; SOUZA, Dandara Queiroga de Oliveira. Mídias e tecnologias no contexto da educação física escolar. In: DORENSKI, Sérgio; LARA, Larissa; ATHAIDE, Pedro (Org.). Comunicação e mídia: história, tensões e perspectivas - Ciências do esporte, educação física e produção do conhecimento em 40 anos do CBCE. Natal-RN: EdUFRN, 2020, p. 57-74. Disponível em:

http://www.cbce.org.br/colecao-40anos.php; Acesso em: 20 de agosto de 2020.

LISBOA, Mariana Mendonça; PIRES, Giovani de Lorenzi. Tecnologias e a formação inicial do professor de educação física: reflexões sobre a educação a distância. Atos de pesquisa em educação, Blumenau, v. 8, n. 1, p. 60-81, 2013.

LÓPEZ-PASTOR, Victor Manuel et al. Alternative assessment in physical education: a review of international literature. Sport, Education and Society, v. 18, n. 1, p. 57-76, 2013.

PAILLÉ, Pierre; MUCHIELLI, Alex. L'analyse qualitative en sciences humaines et sociales. Paris: Armand Colin, 2012.

PENNEY, Dawn et al. Curriculum, pedagogy and assessment: three message systems of schooling and dimensions of quality physical education. Sport, Education and Society, v. 14, n. 4, p. 421-442, 2009. 
VAREA, Valeria; GONZÁLEZ-CALVO, Gustavo. Touchless classes and absent bodies: teaching physical education in times of Covid-19. Sport, Education and Society, 2020. pp. n/a. https://doi.org/10.1080/13573322.2020.1791814

WOODS, Peter. Aspectos sociais da criatividade do professor. In: NÓVOA, Antonio (Org.). Profissão professor. 2 ed. Porto: Porto Ed., 1995, p. 125-153.

UNESCO. Impacto da COVID-19 na educação. 2020. Disponível em:

http://pt.unesco.org/covid19/educationreponse; Acesso em: maio de 2020.

Recebido em: 08 nov. 2020/ Aprovado em: 01 dez. 2020.

\section{Cite como}

\section{(ABNT NBR 6023:2018)}

GODOI, Marcos; KAWASHIMA, Larissa Beraldo; GOMES, Luciane de Almeida. Temos que nos reinventar": os professores e o ensino da educação física durante a pandemia de COVID-19. Dialogia, São Paulo, n. 36, p. 86-101, set./dez. 2020. Disponível em:

https://doi.org/10.5585/dialogia.n36.18659.

\section{American Psychological Association (APA)}

Godoi, M., Kawashima, L. B., \& Gomes, L. A. (2020, set./dez.). Temos que nos reinventar": os professores e o ensino da educação física durante a pandemia de COVID-19. Dialogia, São Paulo, 36, p. 86-101. https://doi.org/10.5585/dialogia.n36.18659. 